\title{
ÄÄNITTÄMINEN, AUTOEROOTTISUUS JA MIKROFONI-IHO
}

Esittämisen ja elokuvan tutkija Allen S. Weiss sanoo, että äänitysteknologioiden synty ei merkinnyt yksinomaan uuden kommunikaatiotavan alkamista, vaan perinpohjaista ajattelemisen uudelleenjäsentymistä (Weiss 1998). Weissin mukaan äänite operoi äänen vahvistamisen, toiston, käänteisyyden, heijastamisen, varjostamisen, dissosiaation, halun ja montaasin maailmoissa, ja itse äänittämisen akti on näissä ulottuvuuksissa perustavalla tavalla liioitteleva ja kaksijakoinen. Äänittäminen häilyy jatkuvasti halun kirjoittamisen ja menneisyyden uudelleenkirjoittamisen väleissä.

Tarkastelen tässä artikkelissa äänittämistä intiiminä itsen kohtaamisena. Tutkin äänittämisaktiin sisältyvää yksityistä kuuntelemista ja tuntemista taktiilisuuden, äänen sensuaalisuuden ja autoeroottisuuden konteksteissa. Väitän, että etenkin kuulokekuunneltu äänittäminen on tallentamisen, siis talteen ottamisen rinnalla miltei aina myös jonkinlaista itsetarkastelua, ja perustan väitteeni mikrofoni-kuuloke-kytkennän kokonaisvaltaista aistimista tuottavaan ruumiillisuuteen. Äänittäessään ihminen kuuntelee äänittämänsä asian sisällä ja reunamilla itseään kuuntelevana kehona, ja kyseinen itsekuuntelu on eräällä tavalla myös autoeroottista itsekosketusta. Kysyn, miten äänittäminen, ympäristön kuuntelu ja itsekosketus kietoutuvat yhteen, ja miten kuuntelu ja tunteminen tuottavat toisiaan äänittämisen hetkellä.

(c) SES \& Taina Riikonen, Etnomusikologian vuosikirja 2016, vol. 28, ss. 1-21. 
Artikkelin teoreettisessa viitekehyksessä yhdistyvät väljästi äänentutkimus, kulttuurintutkimus ja autoetnografia. Ymmärrän kuuntelemisen ympäristön ja itsen kanssa yhteydessä olemisena (vrt. Voegelin 2010), enkä niinkään fysiologisena tapahtumana. Puhun kuuntelemisesta myös filosofi Jean-Luc Nancyn termein "takaisinsointien" (ransk. re-sonance) kohtaamisena (Nancy 2007). Nancylle itsereflektiivisyys on kuuntelua keskeisesti määrittävä tekijä, ja hän puhuu kuuntelemisesta eräänlaisena itseä kohti avautumisena.

Elokuussa 2015 äänitin artikkelia varten suppean autoetnografisen aineiston, jossa kuuntelin ja tallensin neljänä peräkkäisenä päivänä kahta samaa asiaa: metromatkaa Helsingissä välillä Sörnäinen-Helsingin yliopisto (aiemmin Kaisaniemi) ja ylläni olleita nahkahousuja (Metro I-IV 2015, Nahkahousut I-IV 2015) ${ }^{1}$. Housuäänityksen tein niin ikään joka päivä samassa paikassa, hiljaisessa työhuoneessani Helsingin yliopiston tutkijakollegiumissa Fabianinkadulla. Valitsin kyseiset äänittämisen kohteet erityisesti kahdesta syystä. Ensinnäkin, metro ja ylle puetut nahkahousut asettuvat julkinen-yksityinen-akselilla näennäisesti eräänlaisiin ääripäihin: ensin mainittu julkisen liikennevälineen luokkaan, ja jälkimmäinen yksityisen ja henkilökohtaisen objektin kategoriaan. Kuitenkin on selvää, että niin julkisen kuin yksityisenkin rajat häilyvät ja sekoittuvat molemmissa äänityskohteissa, sillä julkisessa liikennevälineessä matkustaminen sisältää aina yksityiseksi verhoutuvia, kanssamatkustajien ulottumattomissa pysyviä kokemuksia ja merkityksiä, ja toisaalta nahkahousut kulttuurisena vaatekappaleena eivät narise yllä vailla yhteisesti luotuja merkityskenttiä. Mustaan nahkaan liitetään länsimaisessa kulttuurikoodistossa muun muassa rajuuden, "rock-henkisyyden", rohkean seksuaalisuuden ja fetisoidun materiaalin merkityksiä (ks. esim. Pohtinen 2012). Äänityskohdevalinnoillani halusin näin ollen osaltani tarkastella julkiseen ja yksityiseen liittyvien merkitysten liudentumisia.

Toiseksi, ruumiillinen oleminen ja kuuntelun suuntautuminen on hyvin erilaista metron ja yllä olevien nahkahousujen tapauksissa. Metro on suuri liikenneväline, jonka sisässä olen, kun taas nahkahousut ikään kuin sulkevat minut tai ainakin osan minusta sisääni. Suhde tilaan ja tilallisuuteen muodostuu näin ollen eri tavoin, mikä vaikuttaa myös kuuntelun havaintoihin sekä ajallisuuteen. Metro kulkee omassa aikataulutetussa rytmissään, mutta nahkahousuissa istuminen laskostuu liikkeisiini vapaammassa ajallisuudessa. Tämän lisäksi nii-

I Äänitykset ovat kuunneltavissa osoitteessa http://www.etnomusikologia.fi/p/av2016.html 
hin niveltyvät materiaalisuudet kuulostavat ja tuntuvat hyvin erilaisilta. Metromatkassa kuuluu asemalaiturin betoni, kiskojen rauta, vaunun metalli, muovi, kumitiivisteet ja moottorijyminä, kun taas nahkahousut ovat kokoaikaisessa kontaktissa omaa ihoa vasten ja soivat pehmeästi narahdellen. Tein molemmat äänitykset kannettavalla Zoom $\mathrm{H}_{4} \mathrm{n}$-nauhoittimella, jossa on XY-stereomikrofonipari 90 asteen kulmassa.

\section{Äänentutkimus ja kuunteleminen}

Kulttuurinen äänentutkimus (engl. sound studies) tarkastelee erilaisia ääneen liittyviä kulttuurisia, sosiaalisia ja materiaalisia ilmiöitä, tapahtumia ja asioita monitieteisesti ja laaja-alaisesti. Mediatutkija Jonathan Sterne sanoo, että kulttuurinen äänentutkimus haastaa ajattelemaan äänten kautta ja läpi; se yllyttää tutkimaan ihmisiä ympäröiviä ilmiöitä ennen muuta soivina. Sternen mukaan kulttuurista äänentutkimusta leimaa lavea tieteidenvälinen uteliaisuus sekä ymmärrys tutkimuksen osittaisesta, tiettyihin valikoituihin aspekteihin keskittyvästä luonteesta ja kuuntelemisen paikantuneisuudesta (Sterne 2012: 4).

Äänentutkimuksen, ja ylipäätään kaikenlaisen äänen kulttuurisen tutkimuksen juuret ovat vahvasti yhtäältä äänimaisematutkimuksessa, joka alkoi 1970-luvulla Kanadassa, ja toisaalta jo 180o-luvun lopulla, "kolonialismin ja nationalismin nosteessa" (Moisala 2013: 19) alkaneessa etnomusikologisessa tutkimuksessa. Äänimaisematutkijat olivat kiinnostuneita äänen, ympäristön, kuulijoiden ja erilaisten yhteisöjen välisistä suhteista (ks. Uimonen 2013). Toisaalta kulttuurinen äänentutkimus limittyy usein myös vahvasti äänitaiteilijoiden tai esimerkiksi radiodokumentaristien työhön. Tätä artikkelia varten tekemäni metroäänitys oli eräänlaista taiteellista äänimaisematutkimusta, äänen ja kaupunkitilan kuuntelua, jossa äänitin ja kuuntelin metroa tutkivana äänitaiteilijana. Olen äänittänyt metroa useita kertoja aina hieman erilaisin tavoittein, mutta nyt tallensin ja havainnoin ennen muuta kuuntelevaa itseäni myös, jolloin tallennus niveltyi osin työhöni äänitaiteilijana (äänimaisematutkimuksen ja äänitaiteen yhteyksistä, vrt. Uimonen 2013: 247-249).

Suomalaisessa kulttuurisen äänentutkimuksen kentässä erityisesti äänimaiseman tutkimus on monipuolista ja vahvaa. Viitisentoista vuotta sitten toteutettu 
laaja tutkimushanke Acoustic Environments in Change tarkasteli eurooppalaisten kylien äänimaisemien muutoksia (ks. esim. Järviluoma 2002). Sata suomalaista äänimaisemaa -hanke sekä sen edelleen työn alla oleva jatkotutkimus Muuttuvat suomalaiset äänimaisemat ovat niin ikään olleet laajoja ääniympäristöjen ja niiden muutoksiin keskittyviä tutkimusprojekteja. Suomalaisen äänimaisematutkimuksen ja kulttuurisen äänentutkimuksen kohteita ovat tämän lisäksi olleet muun muassa akustisen ekologian käsitteet (mm. Vikman 1999; 2007), radion kuuntelemisen käytännöt työpaikoilla (Uimonen 1998) ja kotien äänimaisemat (Kytö 2013). Kuuntelemisen tutkiminen niveltyy kulttuurisessa äänentutkimuksessa ja äänimaisematutkimuksessa usein ympäristön havainnoinnin, sosio-kulttuurisen kuuntelukoodiston ja ääniympäristöihin liittyvien esteettisyyskysymysten tarkasteluun. Ääniympäristön havainnointi, kuuntelun kulttuuriset merkitykset ja ääniin kiinnittyvät esteettiset aspektit ovat käsillä olevan artikkelin kannalta tärkeitä äänittämiseen liittyvän taiteellisen työn kautta.

Äänen filosofiasta kirjoittanut äänitaiteilija Salomé Voegelin (2010) puhuu kuuntelemisesta havainnoimisen ja tulkinnan välimaastona. Voegelin on kiinnostunut nimenomaan äänitaiteen tai pikemminkin sitä kohti suuntaavan äänen kuuntelusta, jota hän kutsuu "keksiväksi havainnoinniksi" enemminkin kuin "todellisuuden" tarkasteluksi (Voegelin 2010: 4). Rohkeasti, joskin jo jossain määrin läpikalutusti Voegelin tarttuu myös visuaalisen ja auditiivisen havaitsemisen eroihin, mistä hän toteaa, että ääni ei niinkään visuaalisen informaation tapaan kuvaile maailmaa tai ilmiöitä, vaan se tuottaa niitä omassa katoavassa hetkellisyydessään. Tässä kohdin Voegelin puhuu soivan "todellisuuden" intersubjektiivisuudesta; se syntyy kuuntelemisen aistimotorisessa prosessissa, ja maailman ja itsen yhteenkietoutuneessa keskipakoisliikkeessä (Voegelin 2010: 10).

Voegelinille äänitetyn äänimaiseman kuunteleminen on "keskittynyttä kuuntelua", ja radikaalia kuuntelua siinä mielessä, että se luo sekä kuunnellun äänen että kuulijansa (Voegelin 2010: 36-37). Ääni on maailma liikkeessä ja prosessissa, ja kuunteleva subjekti asettuu samaan ajan virtaan kuuntelemansa äänen kanssa. Myös filosofi Jean-Luc Nancylle kuunteleminen on ajassa muotoutuvaa itseyttä. Nancy keskittyy Voegelia spesifimmin nimenomaan kuuntelemisen subjektiutta muovaavaan olemuksellisuuteen jättäen kuuntelun esteettiset motiivit sivummalle. "Kun ihminen kuuntelee, hän kurottuu kohti subjektia, jotain (itseä) joka 
identifioituu itseydekseen resonoidessaan itsestä itseen, samanaikaisesti samana ja toisena kuin itse", sanoo Nancy (2007: 9). Hän pohtii äänen värähtelyyn sisältyvää soinnin liikettä, joka hänen mukaansa on "läsnäolon läsnäoloa", eräänlaisessa sisäkkäisessä rakenteessa väräjävää eikä niinkään pysähtynyttä, paikalleen kivettynyttä yksiulotteista läsnäoloa (Nancy 2007: 16). Läsnäoloon kätkeytyvät aina kohtaamisen ja palaamisen elementit, ja edestakaisin aaltoileva ääni palaa aina takaisin, kohtaa kaikki tilan pinnat, itsensä ja kuulijansa, ja värähtelee näin yhä uusissa läsnäolon kehissä. Nancy korostaa sitä, että ääni ei yksinomaan "leviä" tilaan, vaan se avaa aivan oman tilansa, toisin sanoen tuottaa tilaa. Tässä tilan tuottamisen kehyksessä ääni, ja samalla kuuntelu on aina myös tulemista, laajenemista, liikettä, siirtymistä ja läpikulkua.

Voegelinin ja Nancyn kuuntelun intersubjektiivisuutta korostaviin tulokulmiin tuo oman tärkeän lisän mediatutkija Kate Laceyn näkemys, jonka mukaan kuunteleminen - etenkin julkisessa tilassa ja keskustelussa tapahtuva kuunteleminen - on ennen muuta osallistumista, kommunikaatiota ja kriittistä ajattelua (Lacey 2011). Lacey painottaa, että kuuntelu on toimintaa, ja näin ollen se on myös poliittista vuorovaikutusta. Verbi "kuunnella" sisältää aina mahdollisuuden sekä latentimpaan "kuulemisen" tapahtumiseen että jonkin odottavaan ennakoimiseen. Lacey puhuu demokraattiseen yhteiskuntaan kuuluvasta "kuuntelunvapaudesta", ja siitä miten ei-dialogiset ja ei-vuorovaikutukselliset mediat olettavat kaksi erillistä, toisilleen kommunikoimatonta toimijaa: puhujan ja yleisön. Audiovisuaalinen media erilaisine sosiaalisine variaatioineen on mahdollistanut "etäisten toisten" kuuntelun, yhteisöllisen kuuntelun sekä kommunikatiivisten fyysisiä ja sosiaalisia rajoja murtavien tilojen luomisen, mutta "kuuntelunvapaus" vaatii myös eettistä sensibiliteettiä (ks. Lacey 2011: 19). Lacey puhuu "kuuntelunvapaudesta" siis ennen muuta julkiseen tilaan ja keskusteluun liittyvänä toiminnallisuutena, mutta hänen käsitteensä kyseenalaistaa varteenotettavalla tavalla myös niin sanottuun henkilökohtaiseen äänitekuunteluun usein liitetyn passiivisuuden käsitteen. Laceyn mukaan kuuntelu on aina aktiivista, sillä se on osa kommunikaatioprosessia, asettumista tietynlaiseen avoimuuden tilaan. 


\section{Mikrofoni-iho}

"Kuuntelunvapaus" on nykyisin hyvin usein myös valintaa kuunnella äänitettyä ääntä. Äänityshetkellä kuulokemonitoroituna kuunteleminen on muusta ympäristöstä eristetyssä yksityisessä tilassa kuuntelua, jossa äänet muuttuvat eräänlaiseksi omaksi "omaisuudeksi" (ks. Truax 2001). Äänikävelyiden (engl. sound walk) kuulokulmista kirjoittanut äänitaiteilija ja tutkija Andra McCartney sanoo, että mikrofoni-kuuloke-kytkentä on äänittäjälle ennen muuta tapa kuunnella ja tunnustella itseä tietyssä, mikrofonin muovaamassa tilassa (McCartney 2010: 2). Vaikka äänittäjä suuntaa mikrofonin haluamiinsa suuntiin ja siten kontrolloi syntyvää äänimateriaalia, äänitystilanne sisältää kuitenkin (etenkin kenttä-äänityksissä) tietynlaisen ennalta-arvaamattomuuden aspektin. Äänittämishetken erityinen kuunteluasenne onkin eräs tärkeä metodologinen valinta erityisesti äänitetyssä kuuntelukävelyssä (engl. recorded listening walk), jossa tulkitaan ja merkityksellistetään erilaisten ympäristöjen ääniä äänitysteknologian läpi (ks. Uimonen 2011). Artikkelia varten tekemäni metroäänittäminen sivuaa tätä pyrkimystä, mutta se on eksplisiittisemmin yhden tietyn asian äänittämistä, eikä niinkään kokonaisvaltaista, vaihtelevissa ympäristöissä vaeltamista, havainnoimista ja tallentamista. Kuuntelijasubjektin liike ympäristöstä toiseen ei kuulu äänityksessä. Käänsin kuunteluhuomion kuitenkin tarkoituksella itseeni, mutta siten, että kuuntelin itseäni kuuntelemassa, jolloin eräs tarkasteluni kohde oli myös kuuntelun epistemologia.

Äänitysteknologioiden syntyhistoriaa ja merkityksiä modernin länsimaisen ihmisen kuuntelemiselle ja kuuntelemiseen pohjaavalle tiedonmuodostukselle on tutkittu etenkin parin viime vuosikymmenen aikana runsaasti. Erilaisissa tarkastelutavoissa on syvennytty muun muassa äänittämisen teknologisiin ja historiallisiin aspekteihin (esim. Chanan 1995; Théberge 1997; Kittler 1999; Thompson 2002), äänitetyn ihmisäänen "ruumiittomuuden" kysymyksiin (esim. Kahn 1999; Dolar 2006) sekä ajan ja paikan kokemusten muuntumiseen (Emmerson 2004; LaBelle 2008; Sterne 2003). Karkeasti jaotellen äänitysteknologioiden tutkimuksessa voi kenties erottaa kaksi vahvaa yleislinjaa: teknologishistoriallinen ja sosiokulttuurinen tarkastelu. Siinä missä ensin mainittu keskittyy usein kronologisen lineaarisesti ja jonkun yksittäisin toimijan tai valmistajan ympärille jäsentyvään historiallis-tekniseen tarkasteluun, jälkimmäinen, 
sosiokulttuurinen tutkimuslinja voi puolestaan sisältää esimerkiksi erilaisten yhteisöjen, instituutioiden, materiaalien ja käytäntöjen tutkimusta. Toki löytyy myös tutkimusta, jossa kyseiset painotustavat risteävät.

Kulttuurisen äänentutkimuksen erään keskeisen antologian, The Sound Studies Readerin (2012) toimittanut Sterne toteaa, että äänen muuntaminen toiseen materiaaliseen olomuotoon aiheuttaa koko joukon kulttuurisia ja poliittisia kysymyksiä jäljentämisestä liittyen "alkuperäisen" ja "kopion" käsitteisiin sekä ihmisen ja koneen välisiin tekijyysmäärittelyihin (Sterne 2012: 209-210). Pohdinnat siitä, missä määrin äänitysteknologiat "itsessään" muokkaavat ääntä limittyvät monimutkaisiin keskusteluihin erilaisten äänten ja ääniympäristöjen autenttisuudesta, "totuudellisuudesta" ja ainutlaatuisuudesta. Näiden keskusteluiden keskipisteessä värähtelee usein äänen sähköakustinen muunnin, mikrofoni.

Äänentutkija Ian Penman sanoo, että mikrofonin keksimisen jälkeen äänessä ei ole enää mitään alkuperäistä, vaikka oma kysymyksensä toki on, voidaanko mistään alkuperästä puhua ääneen liittyen ylipäätään. Penman sanoo, että mikrofoni tuottaa ainoastaan "ennalta-arvaamattomia elinsiirtoja", "mielipuolisia käännöksiä" ja "kangastuksenomaisia sekoituksia" (Penman 1999: 32). Äänitysteknologiasta teknisin termein puhuvissa kirjoissa sanotaan, että mikrofoni muuttaa ilmassa värähtelevän äänen sähkövärähtelyksi, mutta Penman puhuu (etenkin ihmisäänen tallennukseen viitaten) "aavekohtaamisista kadotettujen äänien ja kaivattujen toisten kanssa" (Penman 1999: 31). Pidän Penmanin mikrofonipuheessa eteeristä toiseuden hohkasta, jota hänen kuvaamansa mikrofoni hengittää sekä sisään että ulos, mutta itse pyrin mikrofonista puhuessani korostamaan tallentamisen aktin lihallisuutta, ja erityisesti kuulo- ja tuntoaistimusten yhteennivoutumista. Koska ihmisen kuulo on aina sidoksissa tuntoaistiin (Connor 1997: 154), mikrofonin kalvo voidaan ymmärtää eräänlaisena toista ihoa luovana pintana, joka reagoi ääniaaltojen värähtelyihin. Mikrofoni-iho on mikrofoni-kuuloke-kytkennän ja kuuntelijan tosiasiallisen ihon yhteenliittymä. Se on orgaaninen kudos, joka resonoi, uudelleensoi ja takaisinsoi äänen ja äänittäjän välisessä aika-tilajatkumossa, äänitysotossa. Mikrofoni-iho sekä vastaanottaa äänen painaumia että uurtaa ääniaaltoihin omaa rajattua otostaan, eräänlaista äänittämisen ajan ja tilan viiltoa. 


\section{Ääni fetissinä}

Äänittäminen toimintana on jo alun alkaen sulkenut sisäänsä tietynlaisen hallinnan, omistamisen, vangitsemisen ja objektivoinnin elementtejä, ja onkin hämmästyttävää miten vähän kulttuurisessa äänentutkimuksessa on tarkasteltu kenttä-äänittämiseen ja äänitaiteeseen niveltyvää ilmeisen keskeistä fetisismin aspektia. Tallennetun äänen ja fetisismin yhteyttä on toki tutkittu etenkin musiikkiäänitteiden kontekstissa (esim. Adorno 1938; Corbett 1994; Wallach 2003) sekä esimerkiksi studioteknologiaan liittyen (Meintjes 2012), mutta yksittäisten äänten, vaikkapa moottoriäänten fetissikaraktääriä ei juuri ole tutkittu. Äänen ja fetisismin pelkkä sivuaminenkin hinkkautuu usein teknologisten aspektien tai instrumenttisuhteen tarkasteluksi, kuten esimerkiksi muusikko-tutkija Franziska Schröderin (2005) pohdinnat musiikin esittämisen, instrumentin soittamisen ja autoeroottisen mielihyvän suhteista, ja jossain määrin myös mediataiteilija Ståhle Stenslien kirjoitukset internet-ympäristössä toteutetusta moniaistisesta kyberseksipuvusta (1996; 2014). Myös etnografit Stuart Favilla ja Joanne Cannon tarkastelevat nahkasoitinimprovisaatiota käsittelevässä artikkelissaan ennen muuta soittimellisuuden ja teknologian suhteita (Favilla \& Cannon 2006).

Tässä artikkelissa puhun fetisismistä seksuaalisuuteen liitetyn fetisismin kontekstissa, jolloin tarkasteluni pääpaino on jonkun materiaalin, esineen tai toiminnan tuottamassa eroottisessa ja sensuaalisessa mielihyvässä, ja vielä kohdennetummin etenkin jonkin rajan, hankauksen, eron sekä objektivisaation merkityksissä (ks. esim. McClintock 1995; Weiss 2011). En käsittele fetissiä tai fetisismiä tässä siis esimerkiksi psykoanalyyttisessä viitekehyksessä, marxilaisena tuotannollisena korvikkeena tai adornolaisittain kulutukseen liittyvänä toimintana.

Yksi harvoista äänifetisismiä käsittelevistä tutkimusteksteistä on John L. Dreverin artikkeli "Sound Fetish Tendencies" (2004). Dreverin mielestä fonografia (engl. phonography) eli väljästi ymmärrettynä ääni(maisema)säveltäminen, kenttääänittäminen, äänitaide ja muut vastaavat tekemisen piirit ovat hahmottaneet tekemisessä heti alusta pitäen eräänlaisena salaoppina, jossa äänittämiseen sisältyy mystifioitua elämän ja kuoleman rajapinnan läsnäoloa. Äänitetyn äänen ja niin sanotun todellisuuden suhdetta ei Thomas Edisonin fonografin syntyaikoina 180o-luvun lopulla ollut sen helpompi käsitteellistää kuin nytkään (Drever 
2004: 6). Tämä salaoppinäkemys lähtökohtanaan Drever tarkastelee äänittämisen käytäntöjä sekä äänitetyn äänen kuuntelemiseen kytkeytyviä merkityksiä ja asenteita. Äänitaiteilijan työ on hänen mukaansa enemmänkin vivisektionistin, eläinkokeita tekevän tutkijan toimintaa kuin (kuolleiden) eläinten täyttäjän työtä (Drever 2004: 6). Elektroakustisia (tai akusmaattisia) säveltäjiä Drever kertoo Michel Chionin kutsuneen fetisisteiksi, jotka pakkomielteisesti takertuvat tietoon äänen lähteestä. Chion itse julistaa olevansa säveltäjä, joka on päässyt täydellisesti eroon kaikista ääneen liittyvistä syy-seuraus-suhteista (ks. myös Schaeffer 2012 [1952]). Äänen objektivoinnin fantasia, ajatus siitä, että äänen voisi "irrottaa" lähteestään on mielestäni kuitenkin juuri äänifetisismiä rujoimmillaan ja paljaimmillaan. Se on myös niin sanotun redusoidun kuuntelemisen (engl. reduced listening) kirkkainta selkäydinnestettä, ja akusmaattisen musiikin historiallis-kulttuurinen perinne. Sellainen elektroakustinen säveltäjä, joka työskentelee ennen muuta itse luomiensa ääniobjektien äärellä onkin eräällä tavalla autoeroottisen äänifetisismin puhdastyylisin masturboija; hän koskee itseään lakkaamatta itse valmistamillaan ääniobjekteilla.

Äänimaisemasäveltämisen tai kenttä-äänittämisen monenlaiset piirit eivät nekään tietenkään ole äänifetisismistä vapaita. Äänitaiteilija Katharine Norman esimerkiksi sanoo, että kenttä-äänittämisen "kauneus" on juuri siinä, että äänittämänsä äänen tai äänimaiseman voi omistaa, että sen voi viedä mukanaan ja kuunnella oman kodin rauhassa, "kaukana [äänityspaikan] todellisuudesta, ilman häiritseviä itikoita tai kitkeriä tuoksuja" (Norman 2004: 61). Normanin lausumassa rakentuu paitsi voimakkaasti fetisoitu tallennettu ja siten ympäristöstään irtilohkaistu ääni, myös ilmeisen räikeä polarisaatio vieraan ja tutun välillä: villin, vaarallisen ja "toisen" luonnon uhkaavuus suhteessa turvalliseen ja tuttuun kotiin. Samalla myös äänittämistapahtuma ja sen analyyttinen kuunteleminen jäsentyvät erillisiksi aktiviteeteiksi. Tällöin äänittämisen fetisismi kietoutuu ennen muuta äänten saalistamisen sekä omistamisen ja hallinnan mahdollisuuksiin, jolloin itse äänittämisaktiin liittyvä fetisistinen mielihyvä saattaa kiinnittyä enemmänkin erikoisten äänten metsästämiseen kuin senhetkiseen kuuntelutapahtumaan. Itselleni kuitenkin juuri äänityshetken jännitteinen ja intiimissä kuulokekuuntelussa hiestyvä kuuntelemisen ruumiillisuus tuottaa paljon suurempaa mielihyvää kuin äänitteiden kuuntelu jälkikäteen äänitysajan- ja paikan ulottumattomissa. Metroa tai nahkahousuja äänittäessä en myöskään tuntenut 
lähteväni poikkeukselliselle saalistusretkelle, sillä molemmat asiat kuuluvat jokapäiväiseen elämänpiiriini. Tutun metromatkan ja päivittäisessä käytössä olevien nahkahousujen äänittäminen herkisti kuitenkin kuuntelevan ihoni ja tuntevan mikrofoni-ihoni aistimaan taajuuksia, joita ei arkisessa vaelluksessa välttämättä huomaa. Äänittäminen myös muokkasi metromatkustamistani ja nahkahousujen pitämistä hyvin performatiiviseksi toiminnaksi; muutuin äänittämistä ja kuuntelua esittäväksi subjektiksi muille ja itselleni.

Toivottavasti mahdollisimman moni, joka tätä artikkelia lukee, tekee sen nimenomaan metrossa nahkahousut jalassa. Viimeistään tässä kohdin olisi hyvä sonnustautua kumpaankin, pukea ylleen sekä nahkahousujen että metron äänet.

\section{Metrojunassa}

Keskeinen osa julkisella liikennevälineellä matkustamista on kulkuvälineen odottaminen. Metron odotusta leimaa omanlaisensa urbaani tunnelma, sillä sitä odotetaan maan alla, monenmoisten löyhkien ja koneellisesti säädeltyjen ilmavirtojen, sirisevien keinovalojen ja kaikuvien betonilaiturien paikassa. Kaikkialla kuuluu jokapäiväisiä kaupungin ääniä: rullaportaiden lonksutusta, ihmisten askelia ja puhetta, erilaisten laitteiden ja koneiden kohinaa, mutta erityistä on se, että äänet kajahtelevat maan alle rakennetussa luolassa. Metroluolan äänimaiseman kenties voimallisin yleispiirre onkin kaiku. Kaikki äänet kaikuvat suuressa tilassa kiviseinistä heijastuneina, ja laiturilla metroa odotteleva kulkija kuulee valikoiman erityisen selkeinä erottuvia ääniä, aina oman kengän alla liikahtelevan kivenmurun hienojakoisena korviin piirtyvästä rahinasta odotuslaiturin etäisimmässä nurkassa seisoskelevan henkilön aivastukseen. Kaikuisuudessaan metrotunnelin akustiikka on ääniä vahvistava ja näin ollen tietynlaiseen yleiseen hälyisyyteen kiihdyttävä, mutta toisaalta myös keskittyneeseen kuunteluun ja hiljentymiseen kutsuva. Pimeinä ammottavat, kivenkatkuista ilmaa henkivät tunnelit tekevät metroasemasta kuitenkin myös aavemaisen ja pelottavankin paikan. Kirjassaan Acoustic Territories äänentutkija Brandon LaBelle (2010) kirjoittaa metron "maanalaisuuden" eräästä suorasta merkityksestä vastarinnan paikkana, maan pinnalla näkyvästi tapahtuvan elämän piiloteltuna vastakohtana, 
pakenemisen tilana. Tässä salamyhkäisyyden ilmapiirissä äänillä on tärkeä merkitys, ja nimenomaan kaikuisuuden tuottamalla kaoottisuudella ja epäselvällä äänimaisemalla (ks. LaBelle 2010: 40). LaBellen mukaan kaikuisuus voimistaa mielikuvituksellisten äänten läsnäoloa, se vääristää perspektiivejä ja hämärtää aikakäsitystä. Äänittäminen tällaisessa jo valmiiksi sameassa, mielikuvitusta kiihottavassa äänitilassa luo ympäristön kuulo-tuntemiseen vielä lisää taajuuksia ja "aavetieteessä", kadonneiden tai kuviteltujen äänien resonansseissa (vrt. Penman 1999: 42) muodostuvia merkitysten kehiä.

Rajasin metron äänityksen siten, että aloitin äänittämisen seisahduttuani asemalaiturille odottelemaan, noin pari minuuttia ennen metron saapumista. Halusin äänittää ennen muuta itse metroa, sen saapumista, liikkeen tuntua, matkustamista sekä kiihdyttämistä ja hidastamista. Näin ollen pyrin säätelemään ihmisäänien läsnäoloa tallenteessa. Ihmisen ruumiillisuus tosin kuuluu korostuneesti mikrofonikuuntelussa, sillä erilaisten kenkien, vaatteiden ja ihmisten mukanaan kantamien tavaroiden äänet erottuvat melko hienojakoisesti mikrofoni-iholla. Kuulokemonitoroituna kuulin tahtomattani myös kohtalaisen hyvin tuntemattomien kanssaodottajien keskusteluja. Tallennusmenetelmäni äänityksissä oli kuitenkin se, että odottaessa asetuin melko lähelle kiskoja - yli turvamerkinnän laiturissa - ja suuntasin mikrofonin kiskoihin sekä tunneliin metron saapumissuuntaan. Metron saapuessa pidin mikrofonia (ilmavirran salliessa) edelleen aivan suoraan kiskoihin ja saapuvaan vaunuun kohdistettuna. Matkan aikana hakeuduin äänittämään lähelle ovia, jolloin pysähtymiset ja lähdöt korostuvat ovien avautumisen ja sulkeutumisen liikkeissä sekä ihmisten kulkemisen äänissä.

Varsinainen metromatka alkaa moniaistisesti koetulla junan saapumisella. Aluksi kiskot syttyvät kihisevään sihinään, sitten junan etuvalojen välähdykset tunnelin seinämiin, ja saman tien lämmin ilmavirta humahtaa kasvoille ja saattelee vierelle liukuvan oranssin junavaunun. Helsingin metrojunat ovat Valmetin ja Strömbergin vuosina 1977-1984 valmistamia M10o ja M200 -sähkömoottorijunia. Länsimetron avatuminen syksyllä 2016 tuo Helsingin metroon myös uusia junia, M30o-junia, joiden valmistaja on espanjalainen CAF-tehdas. Uusia junia on näkynyt koeajossa pitkin kevättä ja kesää.

Helsingin metrojärjestelmän Wikipedia-sivu kertoo seuraavaa: 
Metrojunan kaikki akselit ovat vetäviä ja jokaisella on oma moottori. Jokaisessa vaunussa on kaksi teliä, joissa kummassakin on kaksi akselia. - - Jarrujärjestelmiä metrojunassa on kolme: sähköjarru, paineilmajarru ja kiskojarru. Sähköjarrua käytetään hidastamiseen, ja se toimii kytkemällä ajomoottorit generaattoreiksi ja syöttämällä näin syntyvä sähkövirta erityisiin jarruvastuksiin, joiden tuottama lämpö käytetään kylmänä vuodenaikana matkustamon lämmittämiseen. Paineilmajarrua käytetään junan pysäyttämiseen pienestä nopeudesta ja se toimii samalla sähköjarrun varajärjestelmänä. Telin pyörien välissä sijaitsevat magneettitoimiset kiskojarrut on tarkoitettu hätäjarrutuksiin. (Wikipedia 2016.)

Juuri jarruttamisen sähköinen ääni valtaa metroäänityksen kuulokulman junan saapumista enteilevän kiskojen kihinän jälkeen. Helsingin metrojunien jarrutus kuulostaa hyvin omaleimaiselta; se on toistuvana ylhäältä alas ujeltava sävelliuku. Ääni eroaa huomattavasti esimerkiksi Pariisin tai Lontoon metrojunien tasaisemmin alaspäin kaartuvista jarrutuksen äänistä. Kuulokemonitoroituna jarrutusääni sekoittuu kiskosihinään, jolloin ääneen tulee voimakas metallinen ydin, eräänlainen kova, teräksinen pohjatekstuuri.

Kulttuurintutkija Shelley Trower kirjoittaa kirjassaan Sensing of Vibration: A History of the Pleasure and Pain of Sound (2012) kiinnostavasti siitä, miten fyysikot alkoivat 186o-luvulla puhua "rautatieselkärangasta" (engl. railway spine), jolla he tarkoittivat junan tärinästä ja värähtelystä aiheutunutta olotilaa matkustavassa ihmisessä (Trower 2012: 94). Fyysikot käsitteellistivät ihmisruumista koneiden värähtelyyn herkästi reagoivana mekanismina. Aistimellisena tuntemuksena junan tärinä oli hyvin erilaista kuin hevosvaunussa matkustaminen, ja jotkut tutkijat olivat sitä mieltä, että "jatkuva värähtely" (verrattuna yksittäisten iskujen tuntemiseen) teki matkustavan ihmisen vähemmän tietoiseksi siitä, mitä hänen ruumiilleen oikeastaan tapahtuu. Trower puhuu hyperstimulaatiosta, voimistuneesta pyrkimyksestä kontrolloida ja tuntea värähtelyn pulssi, laskea yksittäiset, vaikkakin erittäin nopeat sykähdykset, ja varoa mahdollista vaaraa (Trower 2012: 97).

Metrojunassa äänittäminen on eräänlaista hyperstimulaatiota. Metro, joka liikkuu nopeammin kuin kaukojuna, ja joka pysähtyy ja kiihdyttää aina muutaman minuutin välein, on äärimmäisen moottorivärähtelyn paikka. Metrovaunu tärisee ja kolisee, se heilahtelee toisinaan kurveissa voimallisestikin, ja ennen 
muuta se humisee ja soi omana suljettuna tilanaan. Kuulokkeista kuunneltuna toistuvat kiihdytykset ja jarrutukset välittävät voimakkaan koneensisäisen äänen tuntuman. Kuuloke-mikrofoni-kytkös eli mikrofoni-iho korostaa vahvasti myös itsen koneisuutta; omaan kuuntelevaan ruumiiseen syntyy suljetun metrovaunun, eräänlaisen koneen sisällä kuuntelevan "koneen" tuntu. Moottoriäänet, jotka laiturilta kuunneltuna soivat osin erillisinä omasta kuuntelevasta ruumiista, resonoivat nyt osana sitä. Resonanssi tuntuu syntyvän sisältäpäin, tärinässä värähtelevän ruumiin takaisinsoidessa, "vastatessa" junan liikkeisiin ja värähtelyihin.

Laiturilla metroa odottaessa kanssaodottavien ihmisten äänet muodostivat suuren osan äänimaisemasta. Metrovaunun sisällä ihmisäänet puolestaan sijoittuivat etäämmälle, sillä kohdistin mikrofonin äänityksissä useimmiten oviin tai lattiarakenteisiin vahvistaakseni vaunun ääniä. Etsin tietoisesti äänityskohtia, joissa kuuluu paljon materiaalisia muutoksia: ovien avautumisia ja sulkeutumisia, tulevia ja poistuvia askeleita ja vaatteiden kahinaa, mutta ennen muuta voimakkaita moottoriääniä. Kyseisillä mikrofonisuuntauksilla loin itselleni yksityisen kuulokulman metrovaunun tilaan ja materiaalisuuteen. Tuotin oman metrovaunun muotoisen ja metrolta kuulostavan kuoren - eräänlaisen soivan puvun - ympärilleni, ja tässä puvussa, akustisessa eriössä tunnustelin kuuntelevaa metromatkustajaruumistani.

Metrojunapuvun taktiilisuus muodostuu ensisijaisesti äänessä ja tärinässä, sillä metron sisällä moottoriäänet ja tärinä hallitsevat äänimaisemaa ja kokonaistilannetta. Äänittäessäni tunnustelin kaikkea mihin koskin fyysisesti (esimerkiksi pystytankoa tai penkinreunaa) äänen läpi, moottorijyminän merkitsemänä. Kyseinen ääni oli oma yksityinen ääneni, vain minun kuuluvillani ja koskettavissa, sillä kuulin sen mikrofoni-ihollani. Autoeroottisen aspektin tähän kuunteluun toi se, että sama äänimaisema oli kaikkien matkustajien kuultavissa, mutta itse saatoin kuunnella ja ennen muuta hipeltää sitä yksityisenä erityispainoksena, jossa tunsin omien mikrofonisuuntausteni painaumat ja uurrot, tietyt voimistetut kohinat ja taajuudet salaa muilta kanssamatkustajilta. Metron kuuntelu tällaisena tietynlaisena äänenä oli siis vain minulle kuuluvaa. Olin oman julkista ja yksityistä tilaa äänittämällä kuunteleva performatiivinen hahmo ja samalla tuon hahmon ulkopuolinen tirkistelijä, eräänlainen voyeuristi. 


\section{Nahkahousuissa}

Erilaisten materiaalien koskemisen ääni on kiehtonut minua pitkään ja olen äänittänyt useita kertoja esimerkiksi silkkiä, samettia, kumia, nahkaa ja muovia eräänlaisina laboratorioäänityksinä, hypistellen ja kuulostellen materiaaleja mikrofonin edessä. Kyseiset äänitykset ovat vakuuttaneet minut siitä, että äänen ja tuntoaistimuksen yhteys on hyvin vahva, mahdollisesti paljon vahvempi kuin esimerkiksi äänen ja kuvan yhteys. Ajatus ylläni olevien nahkahousujen äänityksestä liittyi alun perin erääseen vireillä olevaan tutkimusprojektiini, jossa ajatukseni on tutkia kitkaa sekä äänenä että tuntoaistimuksena, mielihyvän ja kivun tuottajana. Kitkaan, hankaukseen ja hieroutumiseen liittyen kiinnostukseni kohdistuu muutamiin, myös seksuaalisina fetisseinä pidettyihin materiaaleihin, kuten nahkaan, kumiin ja lateksiin, jotka usein tuottavat käyttäjilleen ulkonäön, tuoksun ja tunnun ohella niin ikään äänellistä mielihyvää. Tämän artikkelin aineistoäänitykseen valitsin nahan, sillä saatoin yhdistää tai oikeammin rinnastaa itselleni jokapäiväisen materiaalin tallentamisen jokapäiväisen kulkuvälineen, metron tallentamiseen. Pidin myös ajatuksesta, että sekä metro että nahka sisältävät runsaasti kulttuurisia viitteitä seksuaalisuuteen, ja myös erilaisiin voyeurismien ja fetisismien muotoihin. Metro, tai juna yleisemmin edustaa muun muassa yleistä julkisen ja salaisen seksin paikkaa kulttuuris-pornografisessa kuvastossa. Nahka puolestaan kytketään vaatemateriaalina usein seksuaalisuuteen sekä tietynlaiseen hedonistiseen ja fetisistiseen nautintoon.

Tein äänityksen siten, että istuin toimistotuolilla ja asetin kannettavan äänityslaitteen syliini jalustimen varaan. Jokainen pienikin liikahdukseni kuuluu siis äänitteessä hyvin ja nahka narahtelee lähiäänenä etualalla. Nahan ääni on kuulokekuunneltuna materiaalisesti erityisen monimuotoinen. Siinä soi yhtäältä sileä ja paksu parkkiintuneen, osin pysähtyneen ja kovettuneen pinnan anatomia, ja toisaalta se napsahtelee, narahtelee, maiskahtelee ja läiskähtelee elävän kuuloisesti, kosteaan ihon sisäpuolisuuteen, aiempaan orgaanisuuteensa viitaten. Nahka on jonkun elollisen olennon entistä ihoa; se on tuntenut lämpötilavaihteluita ja ilmanpaineita ja kosketusta. Toisaalta käsiteltynä se on muovautunut miellyttäväksi, yhtä aikaa pehmeäksi ja lujaksi vaatemateriaaliksi. Nahassa on jotain hyvin totaalista, se on eräällä tavalla raakaa materiaalia, toisin kuin esi- 
merkiksi kudottu kangas. Tätä kaikkea ajattelen, kun kuuntelen ja tunnustelen nahkahousuja mikrofoni-ihollani työpöytäni ääressä.

Mikrofoni osoittaa nahan verhoamaan jalkoväliini. Jos liikautan vaikka vain hieman toista reittä, nahka äännähtää voimakkaana lähiäänenä korvissani. Äänitys tuntuu välittömästi autoeroottisesti latautuneelta, sillä housut ovat jo itsessään tiukat ja mikrofoni-kuulokekuulemani äänet soivat myös tekstuuriltaan tiukkoina, synkronissa liikkeideni kanssa. Housut tuntuvat nahkaisemmilta ja myös tiukemmilta näin; nahka tuntuu sisäänsulkevammalta, elävämmältä ja ennalta-arvaamattomammalta näin kuin akustisesti kuultuna. Ääni toisin sanoen vahvistaa ja muokkaa tuntoaistimusta, ja myös toisinpäin: tuntemuksen voimistuessa herkistyn äänille uudenlaisilla taajuuksilla. Tietynlainen audio-taktiilinen seksuaalinen kiihottuminen limittyy äänittämisen ohjailuun, ja kuuntelussani on epäilemättä myös jonkinlaisia narsistisia mielihyväelementtejä. Mikrofoni-ihon läpi kuulen ja tunnen nahan ikään kuin sisältäpäin; tunnen toisin sanoen sen mikroäänimaiseman, joka soi nahkahousun ja varsinaisen ihoni välissä.

Nahkahousujen äänittämisen kuuntelu mahdollistaa minulle position, jossa voin kuunnella omaa nahkaan verhottua alaruumistani yhtä aikaa sekä sen sisäpuolelta tuntien että ulkopuolelta kuulokkeista kuunneltuna. Kuulen itseni nahkaisena objektina ja kuulen itseni myös kuuntelevana subjektina, ja tunnen tästä rajan kuulemisesta suurta mielihyvää. Äänittäjänä minulla on siis fetisistinen suhde siihen nahkaisena soivaan itse/toiseen, jonka kuulen ja tunnen. Kyseiseen fetisismiin kerrostuu ainakin kaksi sisäkkäistä ja osin toisiaan tuottavaa rakennetta: itsen kuuntelu nahkaobjektina mikrofoni-ihon läpi ja kuuntelun kuuntelu "sisältäpäin", kuulokekuuntelulla vahvistettuna tuntoaistimuksena.

Ian Penman puhuu siitä, miten äänitetyn laulun (hänellä esimerkkeinä Billie Holiday ja Frank Sinatra) kuuntelun intiimiys on myös eräänlaista etäisyyttä äänityshetken lauluun ja laulajan ruumiiseen (Penman 1999: 29). Tällainen etäisyys on esineellistettyä "oton" ("take") etäisyyttä, jossa kuulija tuntee kyllä äänessä laulajan läheisyyden, toisin sanoen mikrofonin lähellä laulamisen, mutta sen ruumiillisuus värähtelee erillisessä, jo menneessä aika-tilassa. Nahkahousujen äänitystilanteessa kuunteleminen on toisenlaista, ja etenkin äänellistyvän itse/toinen -ruumiin kuuntelu. Mitään etäisyyttä ei ole, vaan kaikki tapahtuu kuuntelemisen ja tuntemisen nyt-hetkessä, mikrofoni-ihon reaaliaikaisessa sykkeessä. Aika jäsentyy mikrofoni-ihon kosketuksesta vahvistetun reaalituntuisena ja kyseiseen 
vahvistettuun reaalituntuun sekä oman objektiolemuksen kuunteluun sisältyy keskeisesti myös kysymys mielihyvän ja teknologioiden suhteesta, vastaavalla tavalla kuin pornografian äärellä (vrt. Schaschek 2013: 54).

\section{Lopuksi: äänivärähtelevässä kokovartalopuvussa}

Olen tässä artikkelissa tarkastellut äänittämistä autoeroottisena tapahtumana, ja kysynyt, miten äänittäminen, ympäristön kuuntelu ja itsekosketus niveltyvät yhteen, ja miten kuuntelu ja tunteminen tuottavat toisiaan äänittämisen hetkellä. Olen keskittynyt äänittämishetkellä tapahtuvan itsekuuntelun autoeroottisiin aspekteihin, mutta toki itsekuuntelussa on mahdollista tarkastella myös muita kuuntelemiseen kiinnityviä merkityksiä. Eräs kiinnostava tutkimushaara voisi olla yksityisen ja julkisen välimaastoon asettuvan aistimellinen muistaminen, ja sen kytkökset esimerkiksi identiteettiin, tietämiseen ja valtakysymyksiin. Äänentutkija Meri Kytö tarkastelee väitöskirjassaan Kotiin kuuluvaa. Yksityisen ja yhteisen kaupunkiäanitilan risteymät (2013) juuri vastaavanlaisia kysymyksiä erityisesti kaupunkiin sijoittuvien ääniympäristöjen kontekstissa. Itseäni kiinnostaa vielä spesifimmin erityisesti materiaalit, niiden erilaiset tunnut ja tuntuihin kiinnittyvät äänet sekä materiaalien, julkisten tilojen ja aistimellisen tietämisen väliset suhteet.

Toimin metron ja nahkahousujen äänitystilanteissa siten, että kuuntelin ja äänitin, enkä tehnyt muistiinpanoja tallentamisen hetkellä. Kirjoitin havaintoja ja vaikutelmia ylös heti äänitystilanteen päätyttyä. Tämä oli tietoinen valinta, jolla pyrin lisäämään kuuntelun intensiteettiä. Olen toki tietoinen, että vaikka vain hetkeä jälkeenpäin, mutta kuitenkin varsinaisesta kenttätilanteesta irrallaan kirjoitetut havainnot sisältävät jo tietynlaista muistelun kerrostumaa. Ajattelen kuitenkin myös niin, että kieli ja erilaisiksi merkityksiksi muotoutuvat havainnot olivat läsnä kuuntelussani jo äänityshetkellä. Toisin sanoen, vaikka en konkreettisesti kirjoittanut asioita ylös, en voinut välttyä ajattelemiselta ja näin ollen kielessä olemiselta. Eräässä mielessä etsin myös autoetnografian tekemisen tapaa, jossa äänittäminen, kuuntelu ja kielellinen jäsennys ymmärretään samanaikaisiksi toiminnoiksi, mutta ajattelin äänestä kirjoittamisen tapahtuvan äänittämisestä erillään. Eräs ajatus oli myös tehdä äänitteistä jokin erillinen ääniteos. Ääntä käsittelevää etnografista tutkimusta esitetäänkin nykyisin myös yhä useammin 
erilaisissa äänellisissä muodoissa, esimerkiksi radio-ohjelmina tai verkossa julkaistuina ääniesseinä (ks. Järviluoma 2015: 105). Ääniteos metron ja nahkahousujen äänistä voisi tässä tapauksessa olla myös jonkinlainen jatko-osa tutkimukselle tai sen erillinen jälkikirjoitus.

Nahkahousuja äänittäessä mikrofonin asettelu hyvin lähelle oli tietoinen valinta, jolla halusin varmistaa nahan materiaalisuuden lähiäänen kuulumisen. Autoeroottisuuden ja itsekuuntelun teemoihin liittyen halusin myös jo lähtökohtaisesti siivilöidä mikrofoni-ihon kautta ääntä, joka olisi hyvin kokonaisvaltaista ja sisään sulkevaa. Eräänlainen autoeroottinen sääntely ulottui siis myös äänitystilanteen mikrofoniasetteluihin, aivan kuten etnografisessa kenttätyössä ylipäätään: kaikki äänittäminen sisältää aina lukuisia valintoja ja ulossulkemisia (ks. Moisala \& Seye 2013).

Metroäänityksessä junan värähtely, suhina, räminä ja kolina muodostivat yhdessä äänitilan, jossa kuuntelin ja tunsin liikettä eräänlaisena koneisena olentona, taktiilisen kokovartalopuvun läpi kuunnellen. Moottoriäänet ryöpsähtivät mikrofoni-iholleni junan sisuksista voimallisina, ja tunnustelin kokovartalopuvun mikrofonisuuntauksilla esiin uurrettuja virtoja yksityisessä äänitilassani. Kuuntelu-tunnustelun mielihyvä niveltyi julkisen äänimaiseman yksityiseen ääniveistämiseen, tietynlaiseen teknis-esteettis-aistimelliseen kitkaan ja sen sääntelyyn.

Nahkahousuäänityksessä nahan mikrofoni-iholla tuntuvista lähiäänistä muodostui eräänlainen toinen iho, housunahan ja oman varsinaisen ihon väliin kasautuva äänitaktiilinen kerros, jossa saattoi kuulla itsensä samaan aikaan sisä- ja ulkopuolelta. Kyseinen kerros oli kuitenkin eräässä mielessä myös nestemäisempää kuin iho. Se oli oikeastaan eräänlainen erite, kuin hiki, joka syntyi varsinaisen ihoni ja nahkahousujeni väliin. Se oli huokoinen hiki, jossa saattoi tuntea ja kuulla toisiinsa liimautuneen nahan ja ihon.

Äänittäminen ja kuunteleminen mikrofoni-iholla on eräänlaista masturbaatiota äänivärähtelevässä kokovartalopuvussa. Se on tulemista äänten muovaamaksi subjekti-objektiksi, joka kuuntelee ja tunnustelee itseään toisena ja toista itsessään äänessä. Mikrofonin suuntaamisella voi säädellä erilaisia äänimateriaalien laatuja, niiden kosketusten painoa, paineita, sileyttä, karheutta, syvyyttä ja kitkaa. Äänittämisen hetkellä kuunteleminen on toiseksi tehdyn itsen ja itsessä resonoivan toisen tunnustelua. Kuulokemonitoroituun äänittämisen kuunteluun sisältyy voimakas äänifetisistinen taajuus, jossa äänen ja itsen objektivointi, hallitseminen, sääntely sekä samanaikainen kaukaa ja läheltä tarkkailu limittyvät toisiinsa. 


\section{Lähteet}

\section{Tutkimusaineisto}

Metro I-IV 2015. Stereoäänite. 17.8.,18.8., 19.8., 20.8. Metromatka Sörnäinen - Helsingin yliopisto. Äänitys: Taina Riikonen. Tekijän hallussa ja kuunneltavissa osoitteessa http:/ / www. etnomusikologia.fi/p/av2016.html.

Nahkahousut I-IV 2015. Stereoäänite. 17.8., 18.8., 19.8., 20.8. Nahkahousut Helsingin yliopiston tutkijakollegiumissa, Fabianinkatu 24, Helsinki. Äänitys: Taina Riikonen. Tekijän hallussa ja kuunneltavissa osoitteessa http://www.etnomusikologia.fi/p/av2016.html.

\section{Kirjallisuus}

Adorno, Theodor (1938/2006) "On the fetish-character in music and the regression of listening". Schlüsseltexte der Kritischen Theorie. Toim. Axel Honneth. Berlin: Springer.

Chanan, Michael (1995) Repeated Takes: A Short History of Recording and is Effects on Music. London \& New York: Verso.

Connor, Steven (1997) "The Modern Auditory". Rewriting the Self: Histories from the Renessaince to the Present. Toim. R. Porter. London: Routledge.

Corbett, John (1994) "Free, Single and Disengaged: Listening Pleasure and the Popular Music Object". Extended Play: Sounding Off from John Cage to Dr. Frankenstein. Durham: Duke University Press, 32-55.

Dolar, Mladen (2006) The Voice and Nothing More. Massachusetts: The мiт Press.

Drever, John L. (2004) "Sound Fetish Tendencies". Noisegate (12), 4-14.

Emmerson, Simon (toim.) (2004) Music, Electronic Media and Culture. Farnham: Ashgate Books.

Favilla, Stuart \& Cannon, Joanne (2006) "Fetish: Bent Leather's Palpable, Visceral Instruments and Grainger". Contemporary Music Review, 25: 1-2, 107-117.

Järviluoma, Helmi (2002) "Memory and Acoustic Environments: Five European Villages Revisited". Sonic Geographies Remembered and Imagined. Toim. Ellen Waterman. Toronto: Penumbra Press. 
Järviluoma Helmi, Koivumäki Ari, Kytö Meri ja Uimonen Heikki (toim.) (2006) Sata suomalaista äänimaisemaa. Helsinki: sKs.

Järviluoma, Helmi (2013) "Etnomusikologia ja etnografinen kirjoittaminen". Musiikki kulttuurina. Toim. Pirkko Moisala ja Elina Seye. Suomen Etnomusikologisen Seuran julkaisuja 21.

Helsinki: Suomen Etnomusikologinen Seura, 97-118.

Kahn, Douglas (1999) Noise Water Meat: A History of Sound in the Arts. Massachusetts: The MIт Press.

Kittler, Friedrich (2012) "Gramophone". The Sound Studies Reader. Toim. Jonathan Sterne. London: Routledge, 234-247.

Kytö, Meri (2013) Kotiin kuuluvaa. Yksityisen ja yhteisen kaupunkiäänitilan risteymät. Joensuu: ItäSuomen yliopisto.

LaBelle, Brandon (2010) Acoustic Territories. Sound Culture and Everyday Life. London: Continuum. Lacey, Kate (2011) "Listening Overlooked. An Audit of Listening as A Category in the Public Sphere". Javnost - The Public: Journal of the European Insitute of Communication and Culture, $18: 4,5-20$.

McCartney, Andra (2010) Soundwalking and Improvisation. Concordia University, Communication Studies. http://spectrum.library.concordia.ca/6655/ (luettu 4.9.2016)

McClintok, Anne (1995) Imperial Leather: Race, Gender, and Sexuality in the Colonial Contest. New York: Routledge.

Meintjes, Louise (2012) "The Recording Studio as Fetish". The Sound Studies Reader. Toim. Jonathan Sterne. London: Routledge, 265-282.

Moisala, Pirkko \& Seye, Elina (2013) "Musiikintutkija ihmisten keskellä - etnomusikologinen kenttätyö". Musiikki kulttuurina. Toim. Pirkko Moisala \& Elina Seye). Helsinki: Suomen Etnomusikologinen Seura, 29-78.

Nancy, Jean-Luc (2007) Listening. New York: Fordham University Press.

Norman, Katharine (2004) Sounding Art: Eight Literary Excursions Through Electronic Music. Farnham: Ashgate Publishing.

Peltonen, Eeva \& Eskola, Katarina (1997) "Muisto". Aina uusi muisto. Kirjoituksia menneen elämisestä meissä. Toim. Katarina Eskola \& Eeva Peltonen. Jyväskylän yliopisto: Nykykulttuurin tutkimusyksikön julkaisuja, 7-21.

Penman, Ian (1999) "On the Mic. How Amplification Changed the Voice for Good". Undercurrents. London: Continuum, 26-34.

Pohtinen, Johanna (2012) "Ei yhtä arkista kuin maksalaatikko." Kinky seksuaalisuus ja arki. Kansatieteen pro gradu -tutkielma. Turun yliopisto. Historian, kulttuurin ja taiteiden tutkimuksen laitos. 
Schaeffer, Pierre (2012 [1952] In a Search of a Concrete Music [A la recherche de la musique concrète]. Käännös Christine North \& Jonathan Dack. Los Angeles: University of California Press.

Schaschek, Sarah (2013) Pornography and Seriality. The Culture of Producing Pleasure. Basingstoke: Palgrave McMillan.

Schröder, Franziska (2005) "The touching of the touch: performance as itching and scratching a quasi-incestuous object". Extensions: The Online Journal of Embodied Technology. http:/ / www.academia.edu/645055/The_Touching_of_the_Touch-performance_as_itching_and_ scratching_a_quasi-incestuous_object (luettu 10.9.2016).

Stenslie, Ståhle (1996). Wiring the Flesh. Towards the Limits and Possibilities of the Virtual Body. https://stensliehome.wordpress.com/2014/05/17/wiring-the-flesh/ (luettu 10.9.2016).

Stenslie, Ståhle (2013) "Cybersex". The Oxford Handbook of Virtuality. Toim. Mark Grimshaw. New York: Oxford University Press.

Sterne, Jonathan (2003) The Audible Past. Cultural Origins of Sound Reproduction. Durham: Duke University Press.

Sterne, Jonathan (toim.) (2012) The Sound Studies Reader. London: Routledge.

Théberge, Paul (1997) Any Sound You Can Imagine. Making Music/Consuming Technology. Hanover: Wesleyan University Press.

Thompson, Emily (2002) The Soundscape of Modernity: Architectural Acoustics and the Culture of Listening in America 1900- 1930. Cambridge: The міт Press.

Trower, Shelley (2012) Senses of Vibration. The History of Pleasure and Pain of Sound. London: Continuum.

Truax, Barry (2001) "Acoustic Communication Studies at Simon Fraser University". Soundscape: The Journal of Acoustic Ecology 2:2, 11-15.

Uimonen, Heikki. 2011. "Everyday Sounds Revealed: Acoustic communication and environmental recordings". Organized Sound, 16:3, 256-263.

Uimonen, Heikki (2013) "Äänimaiseman ja kulttuurisen äänen tutkimus". Musiikki kulttuurina. Toim. Pirkko Moisala ja Elina Seye. Helsinki: Suomen Etnomusikologinen Seura, 239-254.

Voegelin, Salomé (2010) Listening to Noise and Silence. Towards a Philosophy of Sound Art. London: Continuum.

Vikman, Noora (1999) Akustisen ekologian ekologiset diskurssit. Acoustic Environments in Change working papers 1 / Työraportteja 1. Turun yliopisto, musiikkitiede.

Vikman, Noora (2006) "Suomalaisuuden sydänääniä luonnon helmassa". Sata suomalaista äänimaisemaa. Toim. H. Järviluoma, A. Koivumäki, M. Kytö ja H. Uimonen. Helsinki: sks. 
Vikman, Noora. 2007. Eletty ääniympäristö. Pohjoisitalialaisen Cembran kylän kuulokulmat muutoksessa. Väitöskirja. Tampereen yliopisto. http:/ / tampub.uta.fi/handle/10024/67777 (luettu 16.5.2014).

Wallach, Jeremy (2003) "The Poetics of Electronic Presence: Recorded Music and the Materiality of Sound". Journal of Popular Music Studies, 15:1, 34-63.

Weiss, Allen S. (1998) “Radio Icons, Short Circuits, Deep Schisms." TDR, 40:3, 9-15.

Wikipedia (2016) Helsingin metro. https: / / fi.wikipedia.org/wiki/Helsingin_metro (luettu 4.9.2016).

Weiss, Margot (2011) Techniques of Pleasure: BDSM and the Circuits of Sexuality. Durham \& London: Duke University Press. 